\title{
Stage I Laryngeal Cancer AJCC v8
}

National Cancer Institute

\section{Source}

National Cancer Institute. Stage I Laryngeal Cancer A/CC v8. NCI Thesaurus. Code C133158.

Stage I includes: T1, N0, M0. T1: Suprag lottis: Tumor is limited to one subsite of suprag lottis with normal vocal cord mobility. Glottis: Tumor is limited to the vocal cord(s) (may involve anterior or posterior commissure) with normal mobility. Subglottis: Tumor is limited to the subglottis. N0: No regional lymph node metastasis. M0: No distant metastasis. (AJCC 8th ed.) 